\title{
The role of the F-region vertical drift on the onset time of the equatorial spread F over Ilorin, Nigeria
}

\author{
O A Oladipo ${ }^{1, *}$, J O Adeniyi ${ }^{2}$, I A Adimula ${ }^{1}$, A O Olawepo ${ }^{1}$, A Olowookere ${ }^{1}$, \\ F U SALIFU ${ }^{1}$, S M RAdicella ${ }^{3}$ and B W ReINISCH ${ }^{4}$ \\ ${ }^{1}$ Physics Department, University of Ilorin, P.M.B. 1515, Ilorin, Nigeria. \\ ${ }^{2}$ Faculty of Science and Engineering, Department of Physical Sciences (Physics Programme), \\ Landmark University, P.M.B. 1001, Omu Aran, Nigeria. \\ ${ }^{3}$ Aeronomy and Radiopropagation Laboratory, The Abdus Salam International Centre for Theoretical Physics, \\ Strada Costiera 11, 34014 Trieste, Italy. \\ ${ }^{4}$ Lowell Digisonde International, LLC, 175 Cabot Street, Suite 200, Lowell, MA 01854, USA. \\ *Corresponding author.e-mail: ooladipo@unilorin.edu.ng
}

MS received 16 July 2018; revised 9 January 2019; accepted 14 January 2019; published online 14 May 2019

The equatorial ionosphere often shows the occurrence of plasma-density irregularities and velocity fluctuations with a broad range of scale sizes and amplitudes. These irregularities in the F-region are commonly referred to as the equatorial spread F (ESF) and they are predominantly a night-time phenomenon. The vertical drift of ionisation to higher altitudes post-sunset hours has been suggested to be responsible for the occurrence of these irregularities. We have therefore used all the available ionograms at Ilorin, Nigeria (latitude $=8.48^{\circ} \mathrm{N}$, longitude $=4.67^{\circ} \mathrm{W}$ and $\operatorname{dip}=4.1^{\circ} \mathrm{S}$ ) to study the occurrence of ESF and the effect of the F-region drift on the occurrence of ESF. The available data at Ilorin, though not continuous, cover a period of 6 yrs (i.e., 2002, 2005, 2006, 2007, 2008 and 2010). The F-region vertical drift velocity was estimated starting from around local sunset until the onset of ESF, and the maximum value for a night $\left(V_{Z, \max }\right)$ is used to represent the strength of the $E \times B$ drift for that night. Results obtained showed that the percentage occurrence of ESF increases with the increase in solar activities. A seasonal trend is also observed in the occurrence frequency; occurrence seems to be more frequent during and around the equinox periods. The onset time or the time of commencement (TOC) of ESF was observed to vary from day to day. Also, $V_{Z \text {,max }}$ seems to increase with the increase in solar activities, which in turn influences the TOC of ESF. It was found that the higher the $V_{Z \text {,max }}$, the closer the TOC was found to be to the local time $V_{Z, \max }$. In a few cases, there was no noticeable movement of ionisation prior to the commencement of the ESF, and this might be pointing to the fact that the drifting of ionisation to a higher altitude is not the only condition for the occurrence of ESF. Other conditions that have been identified to play a role in ESF occurrence are thermospheric neutral dynamics, equatorial thermodynamic meridional winds and the post-sunset base height of the F-layer $\left(h^{\prime} F\right)$.

Keywords. Equatorial ionosphere; equatorial spread F; F-region drift; plasma density irregularities. 


\section{Introduction}

Night-time observations of the equatorial ionosphere show the occurrence of plasma-density irregularities and velocity fluctuations with a broad range of scale sizes and amplitudes. These irregularities are referred to as the equatorial spread $\mathrm{F}$ (ESF). ESF manifests as diffused echoes on the night-time ionograms of this region. These irregularities are known to be generated by the plasma-density instability (e.g., Fejer and Kelley 1980; Rishbeth 1981; Kelley 1985, 1989; Fejer 1996; Abdu 2001). The plasma-density instability processes responsible for the generation of ESF have been described by many authors (e.g., Fejer and Kelley 1980 and references therein). ESF is known to be responsible for the amplitude and phase fluctuations of trans-ionospheric signals at GNSS (i.e., Global Navigation Satellite System) frequencies. The occurrence of ESF could lead to the fading of the signals and, in the worst-case scenario, could lead to a complete loss of signals. Many researchers have investigated the occurrence pattern of ESF at different longitudes using ionosonde, $630 \mathrm{~nm}$ airglow observations, radar and GPS data (e.g., Abdu et al. 1998; Hysell and Burcham 2002; Sobral et al. 2002; Chu et al. 2005; Kintner et al. 2007; Sreeja et al. 2009; Susnik and Forte 2011; Paznukhov et al. 2012; Oladipo and Schüler 2013a; Oladipo et al. 2014). The occurrence of ESF has been observed and reported to be seasonal and solar cycle-dependent. For example, Abdu et al. (1998) studied ESF occurrence statistics using long-term data sets from equatorial and low latitude stations in Brazil and Argentina. They observed that ESF occurrence showed both longitudinal and latitudinal dependency. Also, that ESF occurrence rate (i.e., how often ESF occurs) was observed to increase with the increase in solar activities. Most authors have explained the occurrence of ESF in terms of the $E \times B$ drift of ionisation.

In the equatorial region, the electric field $\mathbf{E}$ in conjunction with the Earth's magnetic field $\mathbf{B}$ produces the $E \times B$ force that causes the vertical drift of ionisation. The effect of this forcing on the ionosphere is the well-known thinning down of the post-sunset F2 layer of the equatorial ionosphere. The thinning down of the post-F2 layer is clearly shown in the diurnal plot of electron density at fixed heights and also on the diurnal plot of $\mathrm{HmF} 2$ as the post-sunset decrease in electron density and post-sunset rise in $\mathrm{hmF} 2$, respectively (e.g., see Radicella and Adeniyi 1999). These effects are known to precede the occurrence of ESF, i.e., the bottom side electron density gradient becomes steep during post-sunset hours, which favours the occurrence of ESF. This vertical movement of ionisation by the $E \times B$ force can be pictured as the uplifting of the F-layer to higher altitudes and could be quantified by vertical drift velocity $\left(V_{Z}\right)$. Anderson et al. (2004) described a method of obtaining $V_{Z}$ from ionograms just after the local sunset. In their method, the height rise of the electron plasma frequency contour of $4 \mathrm{MHz}$ from 19:30 to $19: 45 \mathrm{LT}$ is determined, and using velocity $=$ distance/time, $V_{Z}$ is obtained. But the question now is whether there is a minimum value of $V_{Z}$, above which ESF must occur and whether this minimum $V_{Z}$ is solar activity-dependent. Anderson et al. (2004) also used the estimated $V_{Z}$ obtained around 19:30 LT at Ancon in Peru and Antofagasta in Chile to study how this could lead to the occurrence or non-occurrence of ESF.

Therefore, a major focus of the current study, in addition to the occurrence study, is to investigate how $V_{Z}$ affects the occurrence of ESF. Instead of obtaining $V_{Z}$ at 19:30 LT, the value is estimated from around 19:00 LT until just before time of commencement (TOC). The maximum of these values for a particular day is called $V_{Z \text {,max }}$ and is then used to represent the strength of the F-region drift. In addition, the effect of solar activity on the occurrence of ESF is considered.

\section{Data and analyses}

This study is based on the available ionograms recorded at Ilorin, Nigeria (latitude $=8.53^{\circ} \mathrm{N}$, longitude $=4.57^{\circ} \mathrm{E}$ and dipangle $\left.=4.1^{\circ} \mathrm{S}\right)$ over a period of 6 yrs (though continuous data are not available for these years). The years and months together with the number of days for each month for which ionograms are available and the annual average of $F_{10.7}$ are indicated in table 1 . The ionograms used were recorded at 15-min intervals. ESF occurs mainly between the hours of 19:00 and 06:00 LT; hence, ionograms used are restricted to these periods of the day. Ionograms for each night for the period investigated were checked manually to identify the presence of the spread F usually seen as diffused traces on the ionogram. The time of the first appearance of the ESF for each night and the duration of occurrence were recorded. Percentage occurrence (\% occurrence) of the spread $\mathrm{F}$ for each month was calculated using equation (1): 
Table 1. List of years and months used for this study. Number of days for which data are available are indicated in each month. The data used can be categorised into high, low and moderate solar activities.

\begin{tabular}{clr}
\hline \multicolumn{1}{c}{ Available months } & $\begin{array}{c}F_{10.7} \text { annual } \\
\text { average }\end{array}$ \\
\hline 2002 & Jan. (31), Mar. (6) & 179.4 \\
2005 & Nov. (21), Dec. (31) & 91.7 \\
2006 & Jan. (31), Feb. (28), Mar. (28), Apr. (30), May (28) & 80.0 \\
2007 & Jan. (16), Feb. (7), Jun. (16), Jul. (17), Nov. (7), Dec. (30) & 73.1 \\
2008 & Jan. (31), Feb. (21), Mar. (3) & 69.0 \\
2010 & Mar. (6), Apr. (30), May (31), Jun. (31), Jul. (31), & 80.0 \\
& Aug. (31), Sept. (30), Oct. (31), Nov. (11) \\
\hline
\end{tabular}

$$
\% \text { occurrence }=\frac{n}{T} \times 100
$$

where $n$ is the number of days for which spread $\mathrm{F}$ occurred and $T$ is the total number of days in a month for which ionograms are available.

$V_{Z}$ was calculated using the method described by Anderson et al. (2004). This is done by using an increase in the virtual height of the $4 \mathrm{MHz}$ plasma frequency contour over a period of 15 min just after the sunset hour as recorded by the Digisonde located at Ilorin, Nigeria. Figure 1 shows the typical ionograms for 6 August 2010 at 19:30 and 19:45 LT; the ordinary and extraordinary echo traces are shown in red and green, respectively. The thin black line is the calculated for electron-density profile presented as the real (or 'true') reflection height vs. plasma frequency, e.g., Reinisch et al. (2009). In this example, the virtual height at $4 \mathrm{MHz}$ increases by $10 \mathrm{~km}$ within $15 \mathrm{~min}$, corresponding to $V_{Z}=11.1 \mathrm{~m} / \mathrm{s}$ (using velocity equals distance divided by time). In this work, $V_{Z}$ was calculated starting from 19:00 LT until the commencement of the ESF for each day. The maximum of these values is selected and named $V_{Z, \max }$, and the time for this maximum is noted. $V_{Z \text {,max }}$ is then used to represent the strength of the F-region drift for a particular day. The F-region drift velocity data were grouped into four seasons of the year, i.e., March equinox, June solstice, September equinox and December solstice.

\section{Results and discussion}

Figure 2 shows a series of night-time ionograms at Ilorin, Nigeria, for 6 July 2010. There was ESF occurrence on this day and this is clearly seen on the ionograms starting from 22:00 to 23:00 LT.
The development of the spread F started around 21:30 LT but can be seen clearly on the ionogram at 21:45 LT. It is important to mention here that the type of ESF seen at 21:45 LT is referred to as the range spread $\mathrm{F}$ - although there is spread $\mathrm{F}$ occurrence, the critical frequency of the F-layer (foF2) can still be correctly scaled or determined. Frequency spread $\mathrm{F}$ is when there is a spread in the trace only around the height of the critical frequency. This type of spread is not observed at night. The last type of spread $\mathrm{F}$ is known as the mixed spread $\mathrm{F}$ and this occurs when the spread is seen in the whole echo race. This type of spread $\mathrm{F}$ is seen on the ionograms of 22:00 to 23:00 LT on this day. An observation of this study shows that the spread $\mathrm{F}$ is a regular occurrence at Ilorin during both low and high solar activity periods. However, the difference between the occurrence during low and high solar activities is seen in the percentage of occurrence values, duration of occurrence and the TOC of ESF.

Figure 3 shows the monthly percentage occurrence of ESF together with the monthly average of $F_{10.7}$ index value for the months listed in table 1 . The occurrence of ESF seems to be more frequent around equinox months and a kind of minimum is seen around June. This can be seen in the 2010 values in which percentage occurrence reached $100 \%$ in March and in August-November, but attained a minimum of about $86 \%$ in June of the same year. A very slight solar activity trend is also observed in which the occurrence seems to be higher during high solar activity than during low solar activity. A good example is the January values for $2002\left(F_{10.7}=219.9\right), 2006\left(F_{10.7}=\right.$ 80.6), $2007\left(F_{10.7}=80.7\right)$ and $2008\left(F_{10.7}=\right.$ $71.8)$ in which the percentage occurrence values are $79.31,58.06,68.75$ and $66.67 \%$, respectively. 


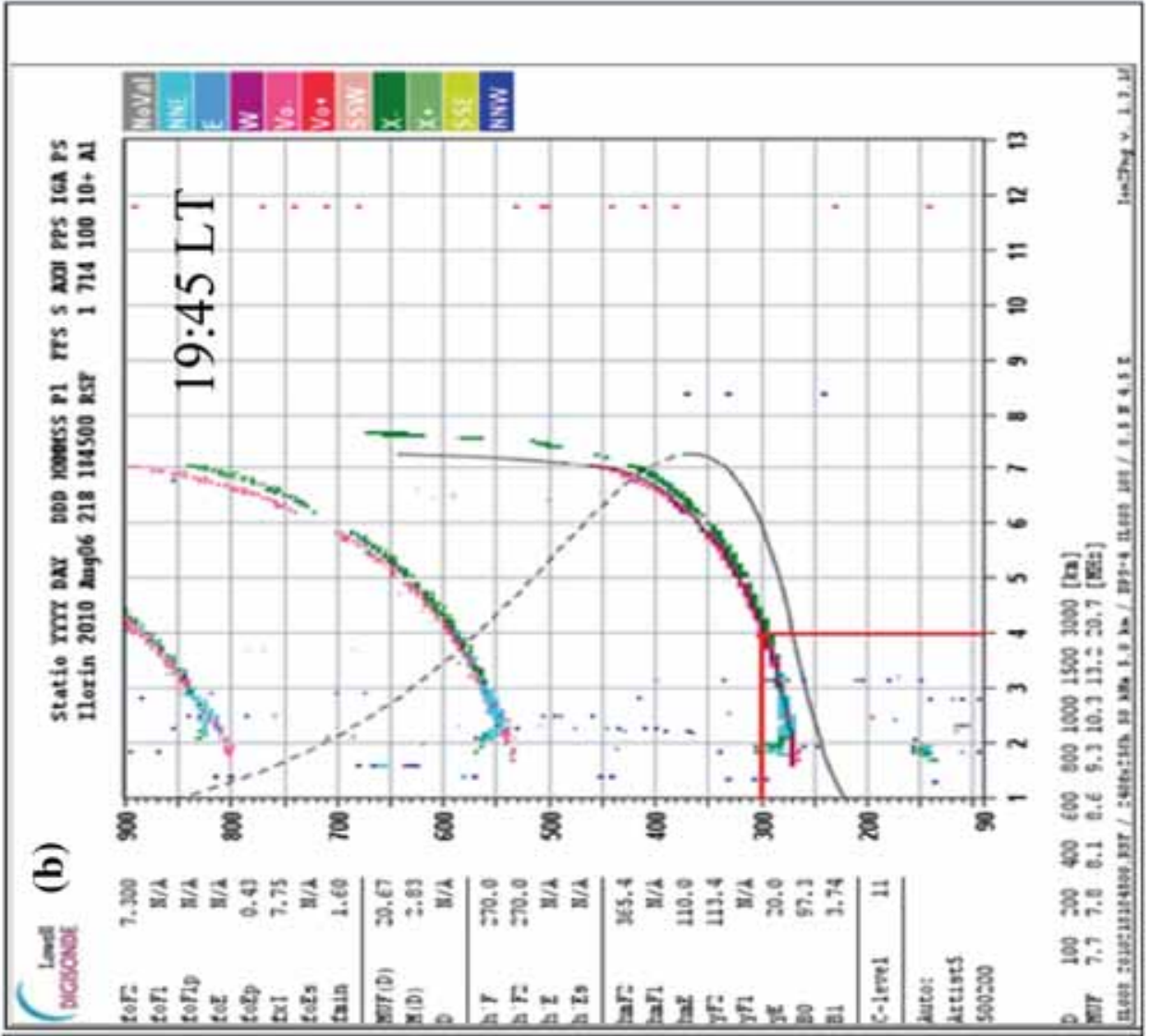

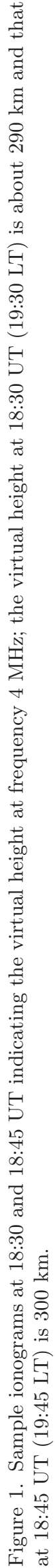



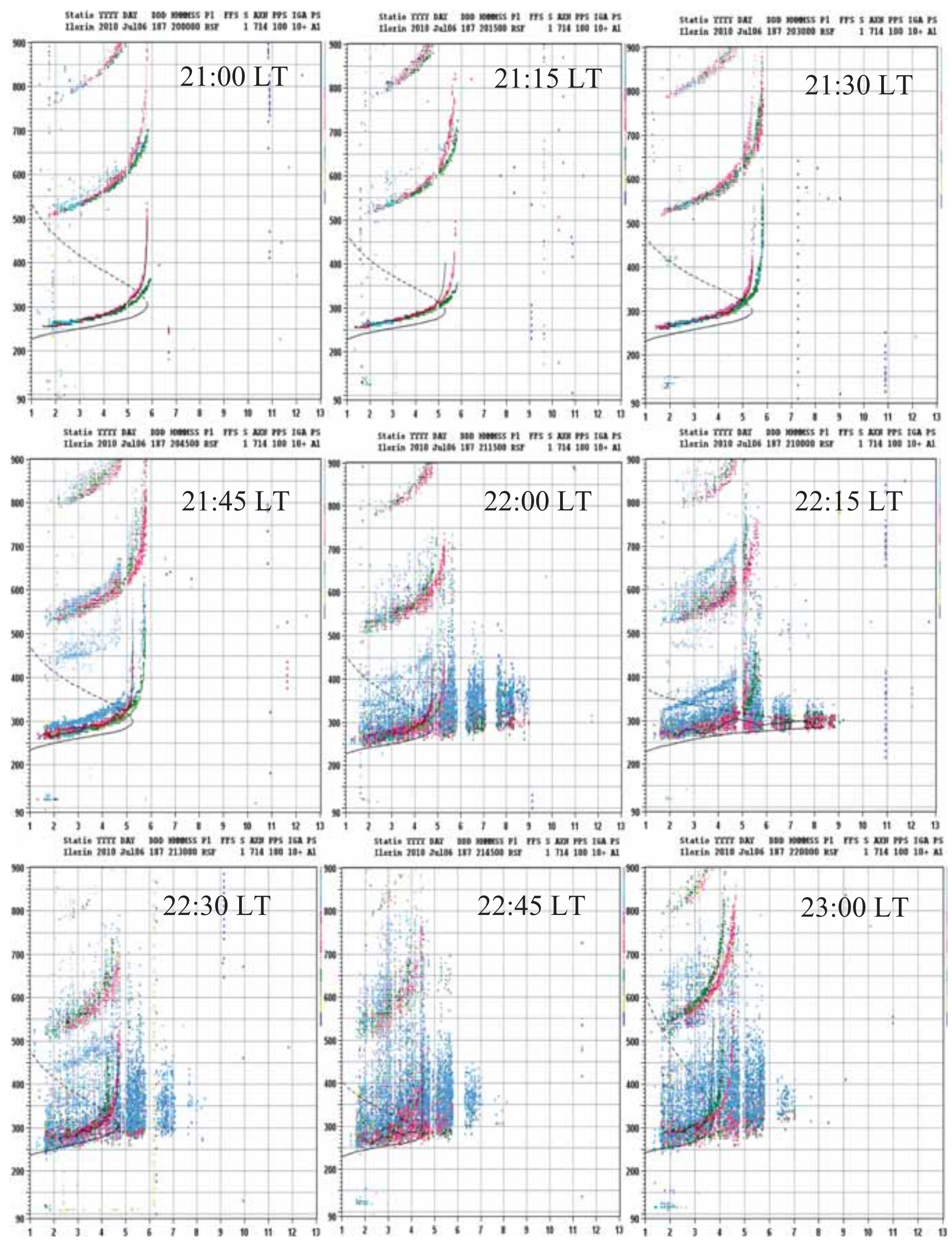

Figure 2. Samples of typical ionograms during pre-midnight hours recorded at Ilorin, 6 July 2010. 


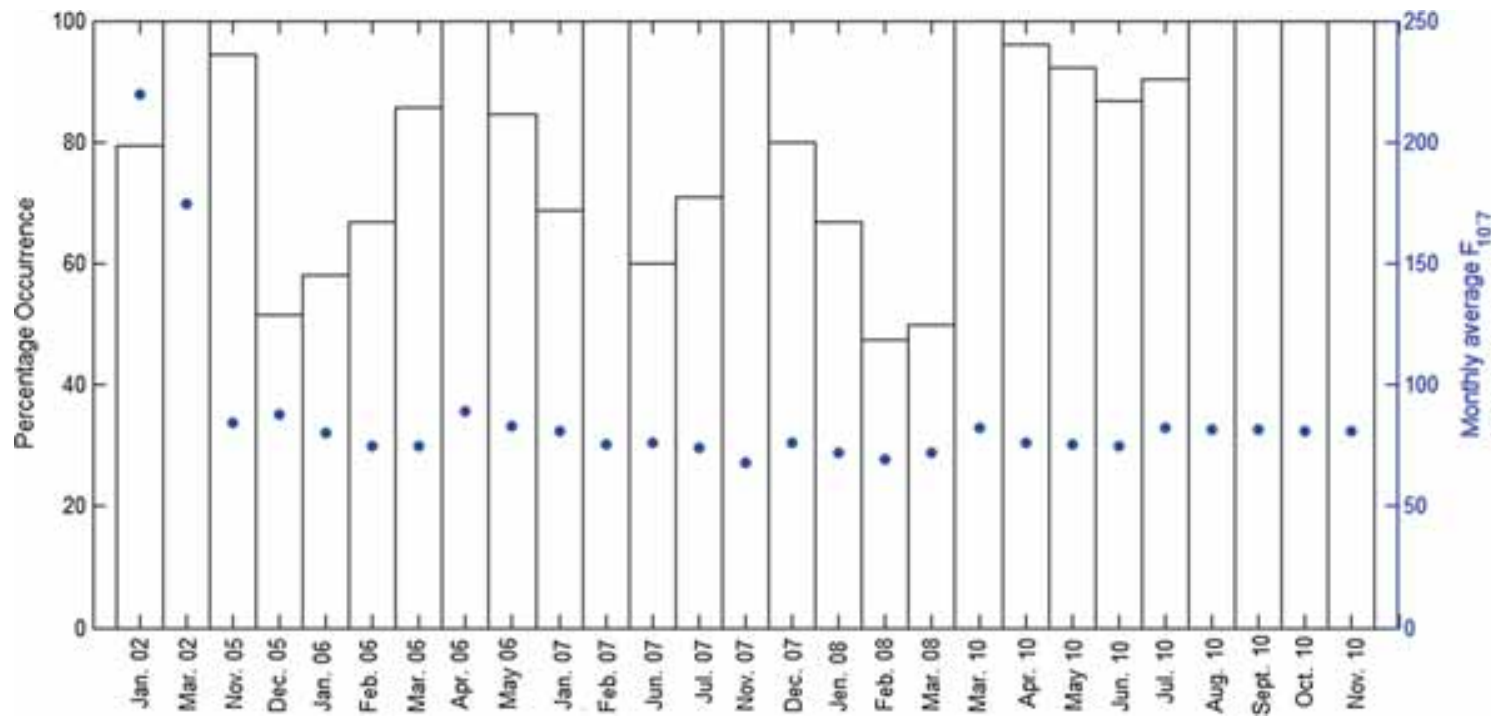

Figure 3. Monthly value of percentage occurrence together with monthly average $F_{10.7}$ value. The scale on the $x$-axis is not continuous - percentage occurrence values for the available months within 6 yrs are shown in the plot. Occurrence is seen to be more frequent in and around the equinox months.

The March values for 2002, 2006, 2008 and 2010 show a similar trend. It is very important to mention that a kind of saturation in the percentage occurrence value is observed, i.e., the increase in percentage occurrence with solar activity is not continuous, instead the value saturates at around moderate solar activity. This can be seen in the values of percentage occurrence during the equinox months.

Figure 4 shows the monthly average of the duration of occurrence of ESF together with the monthly average $F_{10.7}$ value for all months listed in table 1. On estimating the duration of the occurrence of ESF, the period of break in the occurrence of ESF was taken into consideration for the days in which there was a break in the occurrence of ESF between TOC and the last time the ESF was seen for a night. The monthly average duration value observed in this study ranges from about 3 to 9 hrs. No clear seasonal trend is observed, but the value seems to be higher around March and September. On taking the 2010 values, e.g., the duration of occurrence has two peaks and they occur in March and in September with a minimum value in May. As regards the solar activity effect, no clear solar activity trend is observed, but the duration of occurrence seems to be higher during moderate and low solar activity compared to high solar activity periods.

The F-region vertical drift velocity was estimated using the method described by Anderson et al. (2004). The Ilorin ionograms showed that after the local sunset, ionisation begins to gradually move to a higher altitude prior to the commencement of the ESF on most days with ESF; sample ionograms shown in figure 5 illustrate this observation. The ionograms in figure 5 are for 28 March 2010 from 19:00 to 21:00 LT. The dotted horizontal line at a $300-\mathrm{km}$ virtual height and the dotted vertical line at $4.0 \mathrm{MHz}$ are shown for reference, illustrating the rise of the virtual (and real) height for $4 \mathrm{MHz}$ plasma frequency, from below the horizontal line at 19:00 to 19:45 LT and above the line starting from 20:00 LT. This shows the gradual movement of ionisation to a higher altitude prior to the commencement of the ESF at 20:30 LT. For a day like this, the F-region drift velocity can be easily calculated and the value can be used to support the mechanism widely believed to be responsible for the generation of ESF, namely, the movement of ionisation to a higher altitude by the $E \times B$ drift. However, we observed some situations in which there was no noticeable/significant movement of ionisation to a higher altitude prior to the commencement of the ESF, as in figure 6 which shows the ionograms for 4 October 2010 from 18:00 to 20:00 LT. Unlike the observation in figure 5 , in which the entire trace gradually moved from below to above the dotted horizontal line before the commencement of the ESF, the traces at $4 \mathrm{MHz}$ in figure 6 stay below or near $300 \mathrm{~km}$. Despite the absence of vertical drift, the ESF occurred and commenced at 19:15 LT, i.e., even earlier than on the day, as shown in figure 5 , in which the ESF 


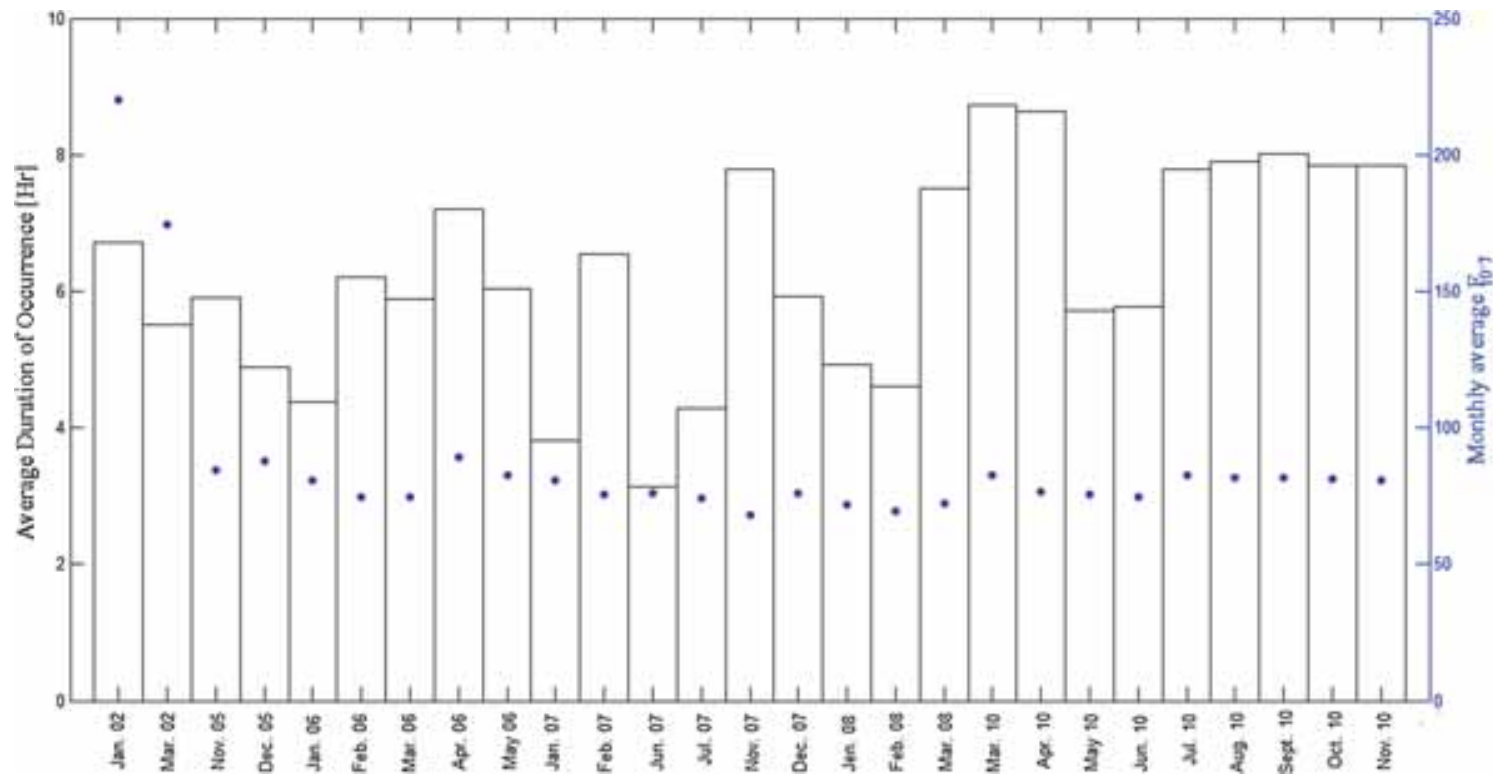

Figure 4. Monthly average of duration of occurrence together with monthly average $F_{10.7}$ value. The scale on the $x$-axis is not continuous - duration occurrence values for the available months within the 6 yrs are shown in the plot. Duration of occurrence is seen to be higher during the equinox periods.

commenced at 20:15 LT. These 2 days were checked for geomagnetic activity and it was found that no geomagnetic storm occurred around these 2 days and the 6 -hr average $K_{\mathrm{p}}$ index value before TOC was $<3$ for the 2 days.

Geomagnetic activity is known to affect the occurrence of plasma-density irregularities which is seen as diffused echoes in the ionogram trace. On investigating the effect of the values of $V_{Z, \max }$ on the TOC of ESF, geomagnetic activity was checked using $D_{\text {st }}$ index values and the criteria/condition given by Hysell and Burcham (2002) was also used, i.e., the previous $6 \mathrm{hr}$ average $K_{\mathrm{p}}$ value $\geq 3$ indicates activity. Storm days and days with geomagnetic activity prior to TOC were excluded. Figure 7 shows the plots of $V_{Z \text {,max }}$ in $\mathrm{m} / \mathrm{s}$ against the TOC in LT for the four seasons of 2010. The number of data points used for the plots are 25, 69, 85 and 7 for March equinox, June solstice, September equinox and December solstice, respectively. The four plots show a trend of $V_{Z, \max }$ decreasing with increasing TOC. This TOC dependence on $V_{Z \text {,max }}$ is more clearly seen during equinoxes. TOC seems to be occurring earlier during equinoxes compared to solstices. Figure 8 shows the plots of $V_{Z \text {,max }}$ in $\mathrm{m} / \mathrm{s}$ against the TOC in LT for the December solstice for (a) $2007\left(F_{10.7}=70.9\right)$ using 25 data points, (b) $2005\left(F_{10.7}=92.7\right)$ using 32 data points and (c) $2002\left(F_{10.7}=188.1\right)$ using 22 data points. $V_{Z, \max }$ during high solar activity seems to be higher than the values during low and moderate solar activity periods. ESF commenced earlier during moderate solar activity compared to low and high solar activity periods. The implication of these results is that in addition to the fact that $V_{Z, \max }$ can be used to predict whether ESF would occur for a particular night, as presented in the studies by Anderson et al. (2004) and Anderson and Redmon (2017), the strength of $V_{Z, \max }$ could also give the delay time, i.e., the duration between TOC of ESF and the time $V_{Z, \max }$ is observed.

Figure 9 shows $V_{Z, \max }$ values against the delay time for the four seasons of 2010. Delay time ranges from $15 \mathrm{~min}$ to about $3 \mathrm{hr}$ in all seasons with the exception of the December solstice perhaps due to scanty data points during the season. Of particular interest is how the value $V_{Z \text {,max }}$ relates to the delay time. A fairly clear trend is observed from figure 9 - delay time seems to be shorter when the $V_{Z \text {,max }}$ value is higher. This trend is clearer during the equinoxes compared to the solstices. Figure 10 shows similar plots as figure 9 for three different levels of solar activities for the December solstice. Due to the limited data availability during the 6-yr period presented in this study, the December solstice plot is presented. The kind of trend observed in figure 9 is seen only in the 2002 plot, i.e., during high solar activity. There is a slight dependence of delay time on $V_{Z, \max }$ in the 2002 plot, and this might be due to the fact that the dependence of delay time on $V_{Z, \max }$ is not that clear during solstices as seen in figure 9 . 

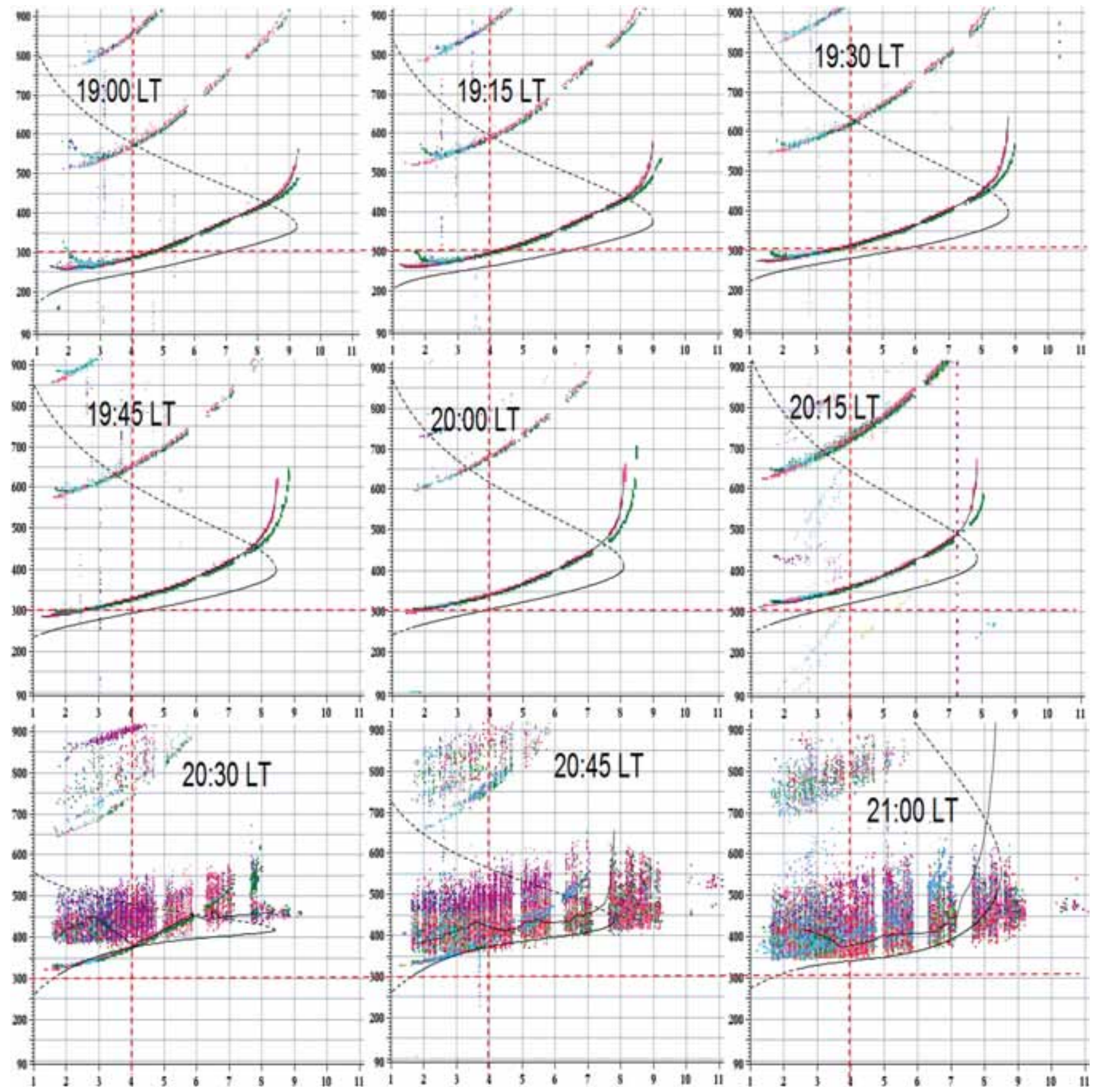

Figure 5. Samples of typical ionograms recorded at Ilorin on 28 March 2010 from 19:00 to 21:00 LT showing movement of ionisation to higher altitude. Vertical and horizontal dotted lines are drawn at $4 \mathrm{MHz}$ and 300 km, respectively. Movement of ionisation is seen on this day prior to the commencement of the ESF.

The post-sunset vertical drift of ionisation to a higher altitude is known to play an important role in the generation and evolution of plasma-density irregularities in the equatorial ionosphere. In fact, almost all features of the equatorial ionosphere can be explained in terms of the vertical drift due to the $E \times B$ force. ESF which is observed as diffused echo on the night ionograms at the equatorial region is a manifestation of the plasma-density irregularities. The occurrence of plasma-density irregularities at night in the equatorial ionosphere has been explained in the terms of Rayleigh-Taylor instability (e.g., Sultan 1996). In the equatorial region, shortly after the local sunset, the magnetic field of the Earth $(B)$ in conjunction with the electric field $(E)$ generated by the F-region dynamo at night gives rise to the $E \times B$ vertical drift of ionisation. This effect is believed to take ionisation to a higher altitude where the conditions are favourable for the generation of the 

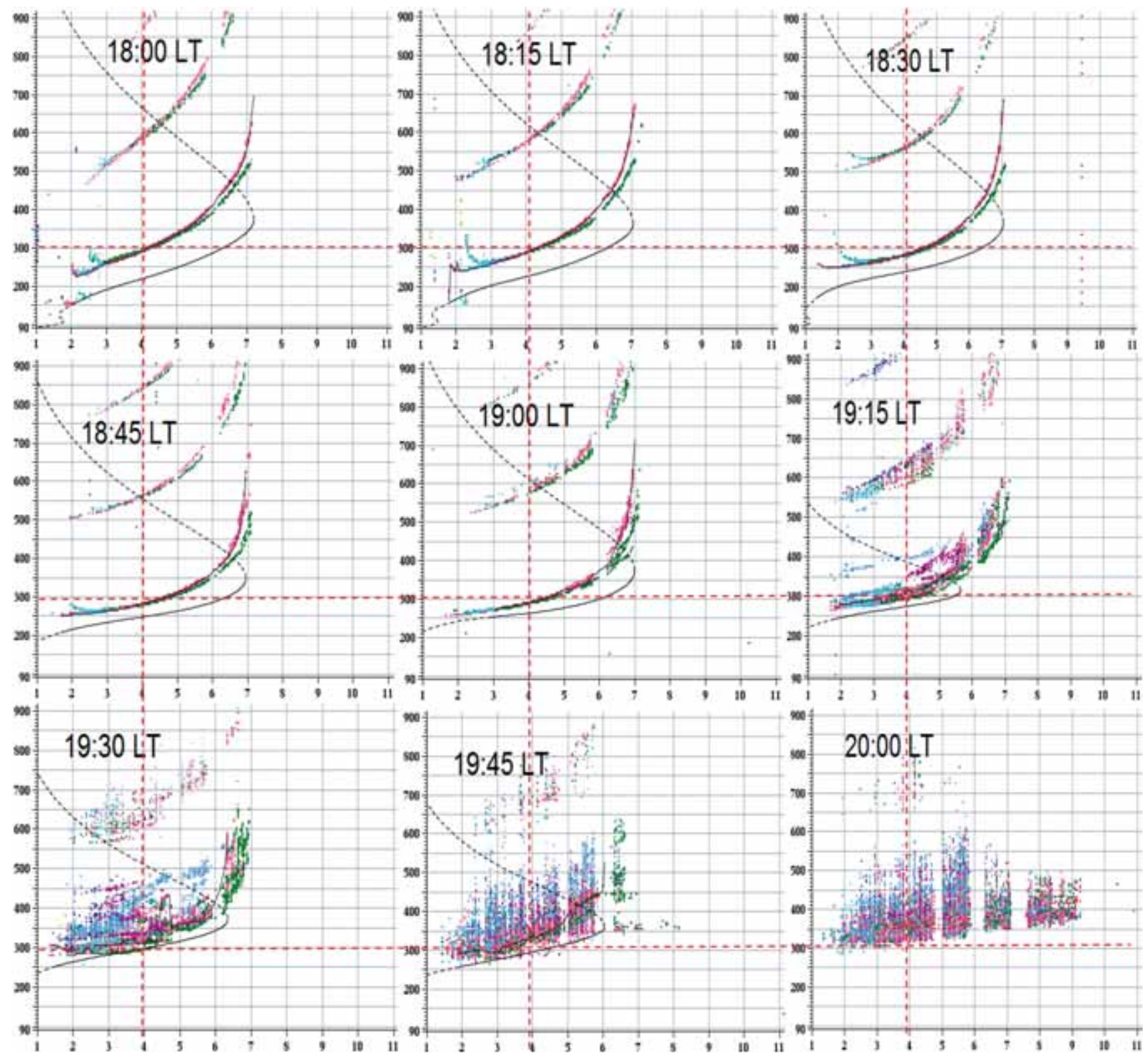

Figure 6. Same as figure 5 for 4 October 2010 from 18:00 to 20:00 LT. Movement of ionisation is not seen on this day prior to the commencement of the ESF.

Rayleigh-Taylor instability process. Results of studies on the lifting of the equatorial ionosphere after the local sunset by the $E \times B$ force have been presented by many authors, e.g., Rajaram and Rastogi (1977), Radicella and Adeniyi (1999), Anderson et al. (2004), Lee and Reinisch (2006) and Anderson and Redmon (2017). For example, the evidence of this lifting is seen as a post-sunset sharp decrease in the diurnal plots of electron density at a fixed height at the F-region heights and also as a post-sunset rise in the height maximum of the F2 layer (hmF2). The results of the current study also show the lifting of the F-region to a higher altitude prior to the commencement of the ESF. This observation supports the mechanism described above as being responsible for the occurrence of plasma-density irregularities which can be seen as ESF on the ionograms. The strength of the $E \times B$ drift (i.e., $V_{Z \text {,max }}$ ) is observed to be higher during high solar activity compared to during low solar activity. This, of course, is due to the fact that the F-region dynamo, which is the source of the $\mathbf{E}$ field during the post-sunset hours, increases linearly with solar activity (e.g., Park et al. 2010).

Seasonal solar activity and geomagnetic effects on the occurrence of ESF have also been reported, 

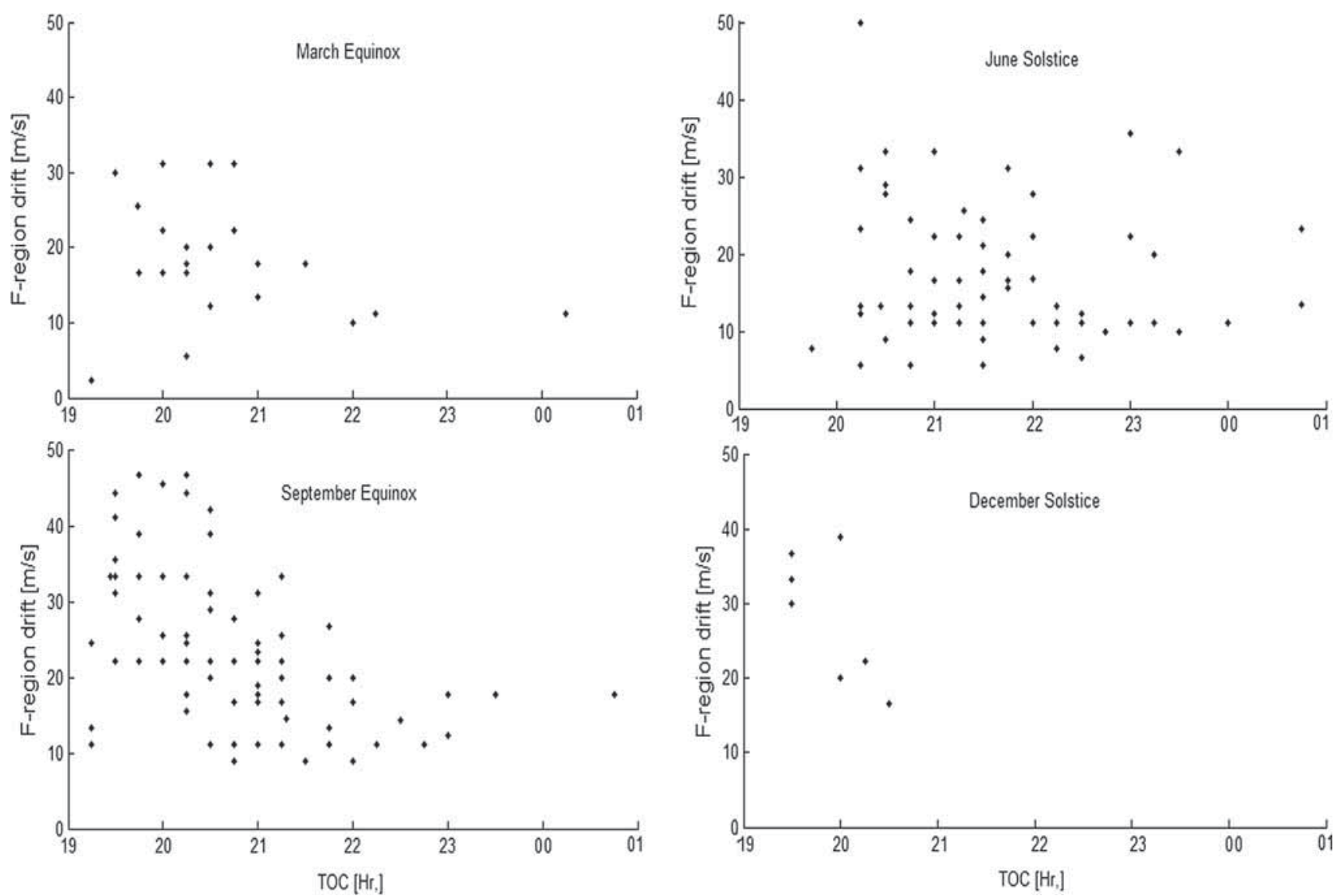

Figure 7. Seasonal plots F-region drift velocity $\left(V_{Z, \max }\right)$ against TOC for the four seasons in 2010 . There seems to be a correlation between $V_{Z \text {, max }}$ and TOC as the TOC value seems to be occurring earlier for high values of $V_{Z \text {,max }}$.

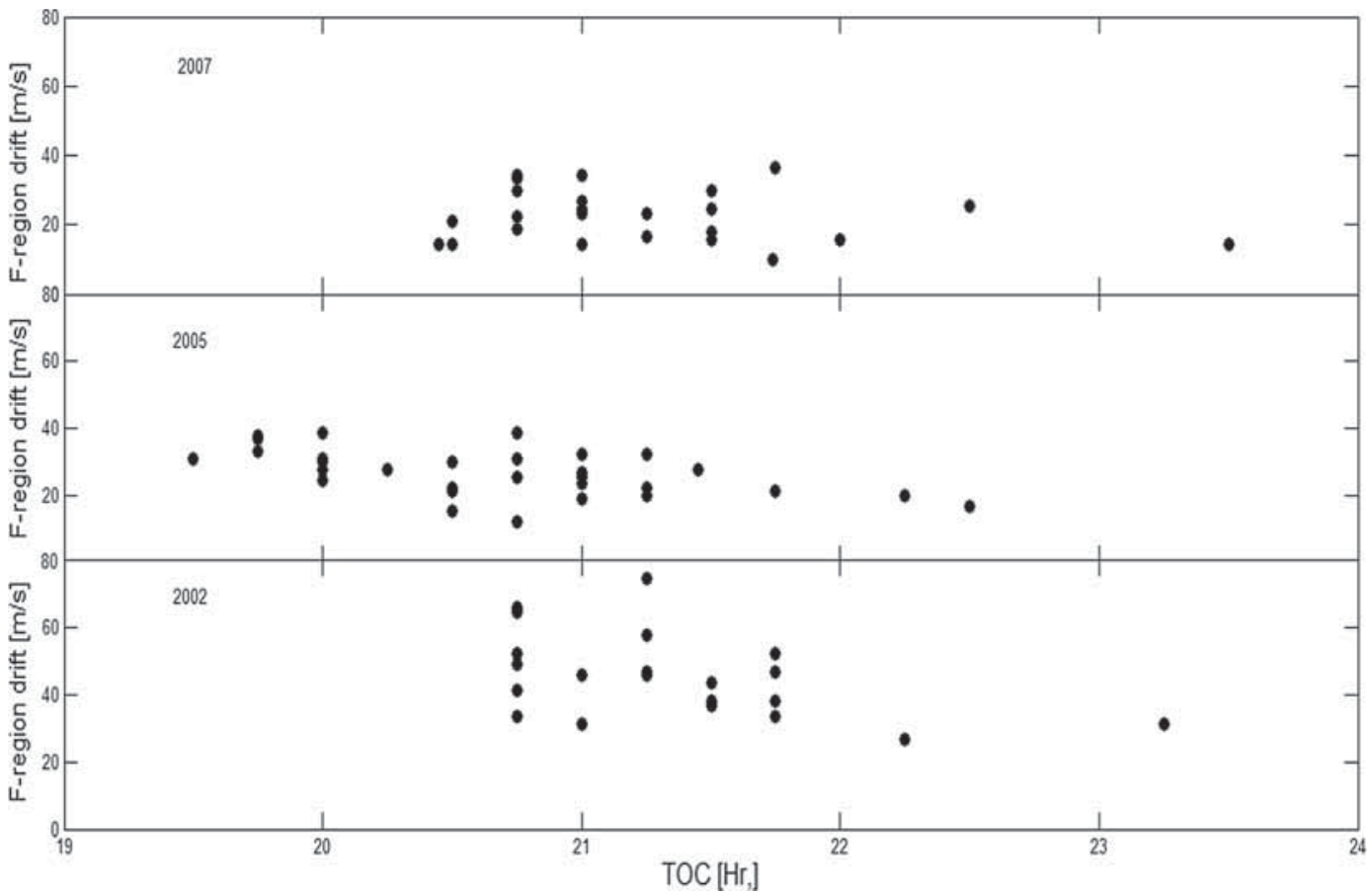

Figure 8. Sample plots F-region drift velocity $\left(V_{Z, \max }\right)$ against TOC for December solstice for (a) 2007 , (b) 2005 and (c) 2002. There seems to be a solar activity trend in $V_{Z \text {, max }}$ with values being higher during high solar than during low solar activity. 

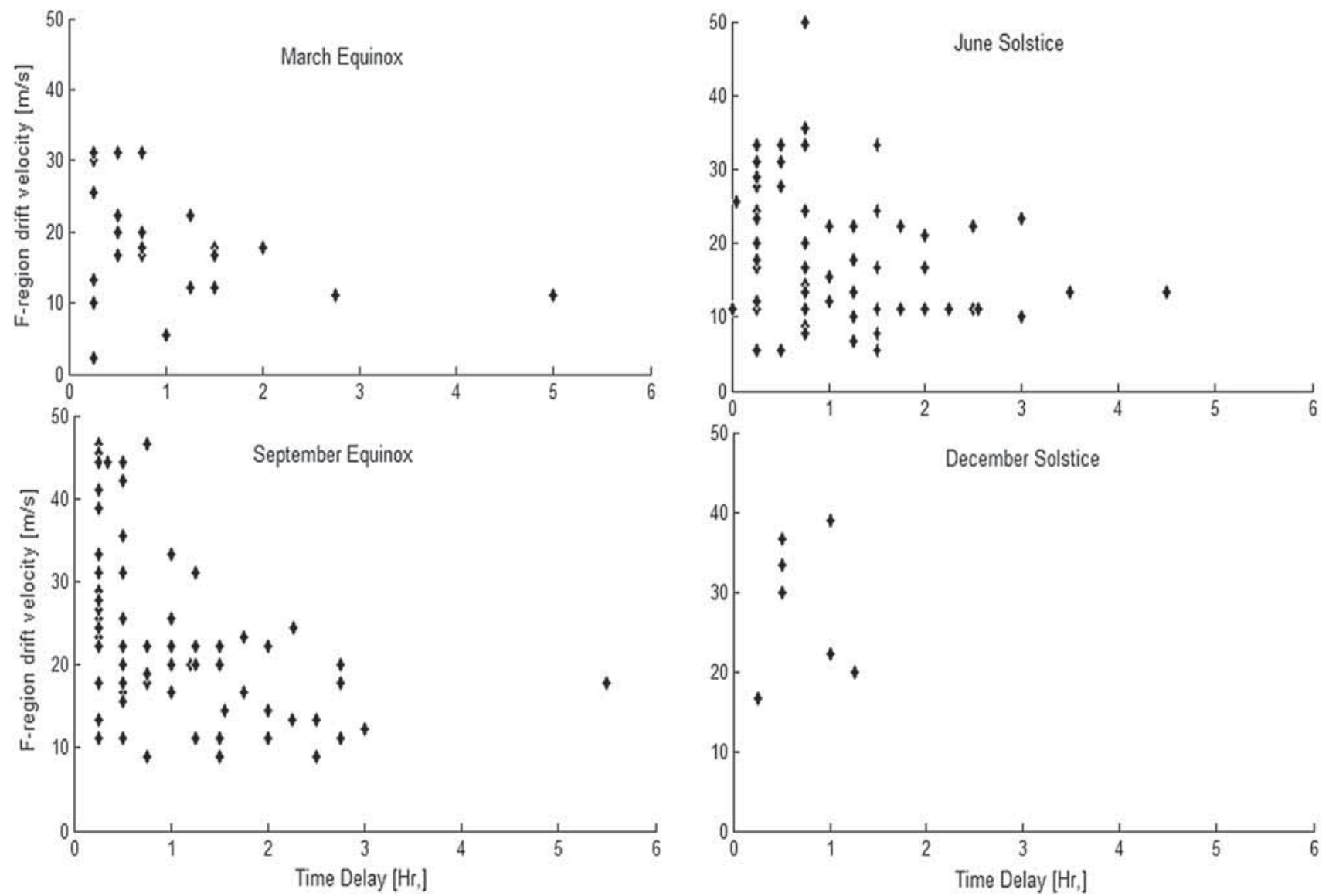

Figure 9. Seasonal plots F-region drift velocity $\left(V_{Z, \max }\right)$ against time delay for the four seasons in 2010 . There seems to be correlation between $V_{Z \text {,max }}$ and time delay as time delay seems to be short when $V_{Z \text {,max }}$ is higher especially during equinoxes.

e.g., Abdu et al. (1998), Hysell and Burcham (2002), Sobral et al. (2002), Chu et al. (2005), Kintner et al. (2007), Sreeja et al. (2009), Susnik and Forte (2011), Paznukhov et al. (2012), Oladipo and Schüler (2013a) and Oladipo et al. (2014); seasonal trends are known to vary with longitude. Equatorial plasma-density irregularities have been reported to be more frequent between October and March in the American sector (Sobral et al. 2002; Chu et al. 2005; Kintner et al. 2007; Seemala and Valladares 2011). In the African sector, the ESF occurrence is more frequent during the equinox period (Susnik and Forte 2011; Paznukhov et al. 2012; Oladipo and Schüler 2013a; Oladipo et al. 2014). The result of the current study also showed that the ESF is more frequent during the equinox period. The solar activity dependence of plasmadensity irregularities as well as the ESF is based on the fact that the level of ionisation increases with the increase in solar activity. This brings about an increase in the background ionosphere, as it is also known to play a role in the occurrence of plasma-density irregularities.
As demonstrated in the current study, $V_{Z, \max }$ is largely an indication of the rise of the $\mathrm{F}$ layer to a higher altitude where the gravitational drift takes over the generation of the ESF. This is believed to be the most plausible explanation for the occurrence of ESF. But the observation reported in this study, in which the ESF occurred without a noticeable movement of ionisation to a higher altitude prior to the commencement of the ESF might be pointing to the fact that other effects could also trigger the occurrence of ESF. Other effects/conditions that have been identified to influence the occurrence of ESF are thermospheric neutral dynamics, equatorial thermodynamic meridional winds and the post-sunset base height of the F-layer $\left(h^{\prime} F\right)$. It is also well known that storm activities could trigger or inhibit plasma-density irregularities, e.g., Aarons and DasGupta (1984), Aarons (1991), Basu et al. (2001), Li et al. (2006), Campos de Rezende et al. (2007) and Oladipo and Schüler (2013b). In fact, magnetic storms are known to enhance or subdue the $E \times B$ drift, 


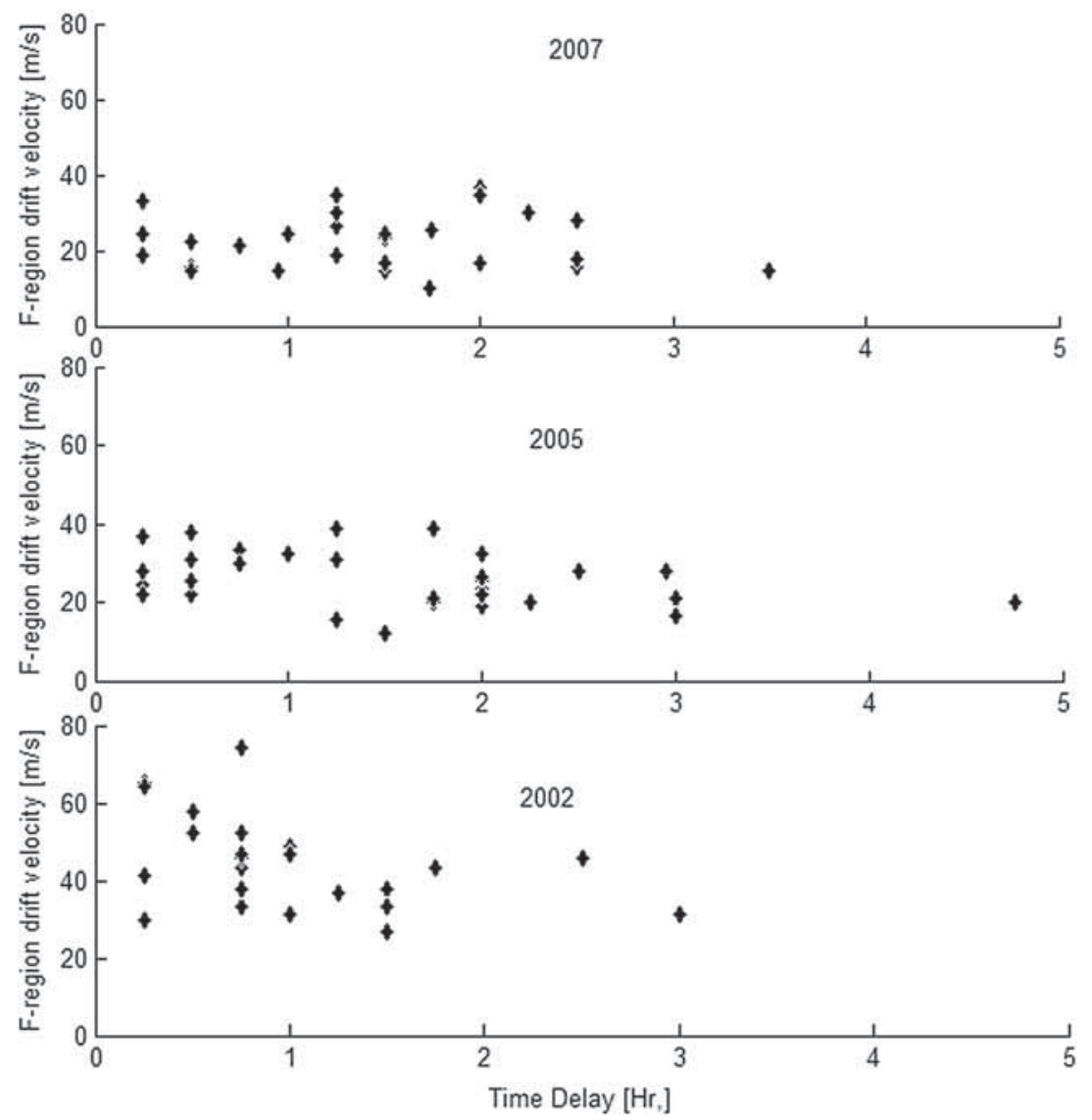

Figure 10. Same as figure 9 for the December solstice for (a) 2007, (b) 2005 and (c) 2002. A slight trend between $V_{Z \text {,max }}$ and time delay is seen only in 2002 .

thereby triggering or inhibiting the occurrence of ESF.

\section{Summary and conclusion}

A study on the occurrence of ESF and the effect of F-region vertical drift velocity $V_{Z \text {,max }}$ on the occurrence of ESF over an equatorial station in the African sector was conducted using all the available ionograms at Ilorin, Nigeria. F-region drift velocity was estimated at every 15 min starting from 19:00 LT until just before the commencement of the ESF on a daily basis, using the method described by Anderson et al. (2004). The maximum value is picked as a representation of the strength of the drift for a particular day. The results obtained can be summarised as follows:

- ESF is a regular occurrence at Ilorin during low, moderate and high solar activities with the frequency of occurrence of ESF increasing with an increase in solar activity.

- Seasonal trend is observed in the occurrence of $\mathrm{ESF}$; the percentage of occurrence as well as the duration of occurrence seem to be higher around equinox periods.

- Movement of ionisation to a higher altitude as indicated by the value of $V_{Z, \max }$ prior to TOC, in most cases, is a prerequisite for the occurrence of ESF, provided the drift is strong enough. However, a few cases with no noticeable movement of ionisation to a higher altitude prior to TOC were also observed.

- There seems to be a linear relationship between $V_{Z, \max }$ and delay time; the higher the $V_{Z, \max }$ value, the shorter the delay time, especially during equinoxes. A slight trend of this kind is seen at the December solstice during high solar activity.

The results obtained in this study support the general consensus that the vertical drift to a higher altitude due to the $E \times B$ force is the major mechanism responsible for the generation and evolution of the ESF. The strength of $V_{Z \text {,max }}$ can be used to determine whether the ESF will occur for a particular night. In addition, the magnitude of $V_{Z, \max }$ helps determine how close TOC 
will be to the time $V_{Z \text {,max }}$ is observed. However, in a few cases, there was no noticeable movement of ionisation to a higher altitude prior to the commencement of the ESF, and this could be pointing to the fact that, in addition to the role $E \times B$ drifting of ionisation to a higher altitude plays in seeding and evolution of ESF, other effects exist that could as well bring about the occurrence of ESF. Other effects/conditions that have identified to play a role in the occurrence of ESF are thermospheric neutral dynamics, equatorial thermodynamic meridional winds and the post-sunset base height of the F-layer $\left(h^{\prime} F\right)$.

\section{Acknowledgements}

The authors would like to acknowledge the University of Ilorin for the continuous support for the Ilorin Ionospheric Research Station. The 10.7-cm solar flux index data and $D_{\text {st }}$ values are available for public access from NASA at https://omniweb. gsfc.nasa.gov/form/dx1.html. The 2010 ionograms data are available at the Lowell GIRO Data Center, https://lgdc.uml.edu/common/DIDBMonth ListForYearAndStation? ursiCode=IL008 $\backslash \&$ year $=$ 2010.

\section{References}

Aarons J 1991 The role of the ring current in the generation or inhibition of equatorial F-layer irregularities during magnetic storms; Radio Sci. 26 1131-1149.

Aarons J and DasGupta A 1984 Equatorial scintillations during the major magnetic storm of April 1981; Radio Sci. $19731-739$.

Abdu M A 2001 Outstanding problems in the equatorial ionosphere-thermosphere electrodynamics relevant to spread F; J. Atmos. Sol.-Terr. Phys. 63 869-884.

Abdu M A, Sobral J H A, Batista I S, Rios V H and Medina C 1998 Equatorial spread F occurrence statistics in the American longitudes: Diurnal, seasonal and solar cycle variations; Adv. Space Res. 22(6) 851-854.

Anderson D N and Redmon R J 2017 Forecasting scintillation activity and equatorial spread F; Space Weather 15(3) 495-502.

Anderson D N, Reinisch B, Valadares C, Chau J and Veliz O 2004 Forecasting the occurrence of ionospheric scintillation activity in the equatorial ionosphere on a day-to-day basis; J. Atmos. Sol.- Terr. Phys. 66 1567-1572.

Basu S, Basu S, Valladares C E, Yeh H C, Su S Y, Mackenzie E, Sultan P J, Aarons J, Rich F J, Doherty P, Groves K M and Bullett T W 2001 Ionospheric effects of major magnetic storms during the international space weather period of September and October 1999: GPS observations, VHF/UHF scintillations, and in situ density structures at middle and equatorial latitudes; J. Geophys. Res. 106(A12) 30389-30414.

Campos de Rezende L F, Rodrigues de Paula E, Stacarini Batista I, Jelinek Kantor I and Tadeu de Assis Honorato Muella M 2007 Study of ionospheric irregularities during intense magnetic storm; Rev. Bras. Geof. 25(Suppl. 2) 151-158.

Chu F D, Liu J Y, Takahashi H, Sobral J H A, Taylor M J and Medeiros A F 2005 The climatology of ionospheric plasma bubbles and irregularities over Brazil; Ann. Geophys. 23 379-384.

Fejer B G 1996 Natural ionospheric plasma waves; In: Modern ionospheric science (eds) Kohl H, Rüster R and Schlegel K, European Geophysical Society, KatlenburgLindau, Germany, pp. 216-273.

Fejer B G and Kelley M C 1980 Ionospheric irregularities; Rev. Geophys. Space Phys. 18(2) 401-454.

Hysell D L and Burcham J D 2002 Long term studies of equatorial spread F using the JULIA radar at Jicamarca; J. Atmos. Sol.-Terr. Phys. 64 1531-1543.

Kelley M C 1985 Equatorial spread F: Some recent results and outstanding problems; J. Atmos. Sol.-Terr. Phys. 47 $745-752$.

Kelley M C 1989 The earth's ionosphere plasma physics and electrodynamics; Academic Press, San Diego, CA, USA.

Kintner P M, Ledvina B M and de Paula E R 2007 GPS and ionospheric scintillations; Space Weather 5 S09003, https://doi.org/10.1029/2006SW000260.

Lee C C and Reinisch B W 2006 Quiet-condition hmF2, $\mathrm{NmF} 2$, and $\mathrm{B} 0$ variations at Jicamarca and comparison with IRI-2001 during solar maximum; J. Atmos. Sol.Terr. Phys. 68 2138-2146.

Li G, Ning B, Wan W and Zhao B 2006 Observations of GPS ionospheric scintillations over Wuhan during geomagnetic storms; Ann. Geophys. 24 1581-1590.

Oladipo O A and Schüler T 2013a Equatorial ionospheric irregularities using GPS TEC derived index; J. Atmos. Sol.-Terr. Phys. 92 78-82.

Oladipo O A and Schüler T 2013b Magnetic storm effect on the occurrence of ionospheric irregularities at an equatorial station in the African section; Ann. Geophys. 56(5) A0565.

Oladipo O A, Adeniyi J O, Olawepo A O and Doherty P H 2014 Large-scale ionospheric irregularities occurrence at Ilorin Nigeria; Space Weather 12 300-305.

Park J, Lühr H and Min K W 2010 Characteristics of F-region dynamo currents deduced from CHAMP magnetic field measurements; J. Geophys. Res. 115 A10302.

Paznukhov V V, Carrano C S, Doherty P H, Groves K M, Caton R G, Valladares C E, Seemala G K, Bridgwood C T, Adeniyi J O, Amaeshi L L N, Damtie B, D'Ujanga Mutonyi F, Ndeda J O H, Baki P, Obrou O K, Okere B and Tsidu G M 2012 Equatorial plasma bubbles and L-band scintillations in Africa during solar minimum; Ann. Geophys. 30 675-682.

Radicella S M and Adeniyi J O 1999 Equatorial ionospheric electron density below the F2 peak; Radio Sci. 34(5) 1153-1163.

Rajaram G and Rastogi R G 1977 Equatorial electron densities-seasonal and solar cycle changes; J. Atmos. Sol.Terr. Phys. 39 1175-1182. 
Reinisch B W, Galkin I A, Khmyrov G M, Kozlov A V, Bibl K, Lisysyan I A, Cheney G P, Huang X, Kitrosser D F, Paznukhov V V, Luo Y, Jones W, Stelmash S, Hamel R and Grochmal J 2009 The new digisonde for research and monitoring applications; Radio Sci. 44 RS0A24, https:// doi.org/10.1029/2008RS004115.

Rishbeth H 1981 The F-region dynamo; J. Atmos. Sol.-Terr. Phys. 43387.

Seemala G K and Valladares C E 2011 Statistics of total electron content depletions observed over the South American continent for the year 2008; Radio Sci. 46 RS5019, https://doi.org/10.1029/2011RS004722.

Sobral J H A, Abdu M A, Takahashi H, Taylor M J, de Paula E R, Zamlutti C J, de Aquino M G and Borba G L
2002 Ionospheric plasma bubble climatology over Brazil based on 22 yr (1977-1998) of $630 \mathrm{~nm}$ airglow observations; J. Atmos. Sol.-Terr. Phys. 64 1517-1524.

Sreeja V, Devasia C V, Ravindran S and Sridharan R 2009 The persistence of equatorial spread $\mathrm{F}$ - an analysis on seasonal, solar activity and geomagnetic activity aspects; Ann. Geophys. 27 503-510.

Sultan P J 1996 Linear theory and modeling of the RayleighTaylor instability leading to the occurrence of equatorial spread F; J. Geophys. Res. 101(A12) 26875-26891.

Susnik A and Forte B 2011 Ionospheric scintillation activity measured in the African sector; In: Paper presented at General assembly and scientific symposium, XXXth URSI, Istanbul, Turkey.

Corresponding editor: Amit Kumar Patra 